\title{
Apuntes sobre Roberto Arlt en los años treinta,
}

\section{de Laura Juárez Buenos Aires: Simurg, 2oro.}

\author{
- María Fernanda Alle / Universidad Nacional del Litoral - Universidad Nacional de Rosario - Conicet \\ yfernandaa@hotmail.com
}

Siempre me resulta atractivo detenerme en la lectura de los epígrafes con que cada autor decide comenzar su libro. Ellos no sólo están allí como claves para que el lector pueda predecir hacia dónde irá el texto; también nos muestran el ejercicio de lectura y de selección que opera cada autor sobre su «biblioteca personal». Los dos epígrafes escogidos por Laura Juárez para su libro Roberto Arlt en los años 30, van aún más lejos en este camino pues, además, permiten ilustrar la eficacia y la potencia de su trabajo crítico. En ellos se anticipan, inteligentemente, no sólo las hipótesis generales y los derroteros argumentativos que seguirá para sostenerlas sino también las inflexiones singulares que efectuará sobre los saberes previos para complejizarlos, enriquecerlos, y lograr, en última instancia, una nueva mirada sobre la obra y la figura de Roberto Arlt. Ya desde este espacio inicial, pero para nada accesorio, se puede apreciar el carácter innovador de la investigación de Laura Juárez. El primero de esos epígrafes es una cita del texto "Presencia de Miguel de Unamuno» de Borges, en el que el escritor señala, contrariamente a los juicios más comunes y extendidos, que para conocer "de veras» a un autor hay que buscarlo en sus obras «menos felices», "pues en ellas (...) está más el autor que en aquellas otras que nadie vacilaría en firmar» (I3). El segundo es un breve pasaje del famoso prólogo a Los Lanzallamas en el cual Roberto Arlt afirma que su deseo de escribir una novela al modo de Flaubert, compuesta de "panorámicos lienzos», se vuelve irrealizable en ese presente signado por el desmoronamiento del «edificio social». En primer lugar, la frase de Borges opera como disparador del pensamiento crítico de Juárez, que centra su atención, y recorta su objeto de estudio, en la producción de Arlt delimitada entre los años 1932 y 1942 — precisamente el lugar menos estimado de su obra y, por ende, el menos transitado por la crítica- para mostrar que allí se producen importantes cambios respecto de su novelística de la década anterior; cambios que reconfiguran todo su proyecto artístico y obligan a interrogar ciertos lugares comunes del pensamiento, extendidos en torno a su imagen de escritor y a su obra. Así, distanciándose de los juicios previos que señalan a esta parte de la producción arltiana como de «menor valor literario», Juárez sostiene que desde allí puede obtenerse una nueva visión acerca de la constitución de su proyecto creador y de su figura del escritor. Con la cita de Los lanzallamas, por su parte, la autora repone las ideas generales del autor que sustentaron el proyecto novelístico de los años $20 \mathrm{y}$, al mismo tiempo, abre el panorama para considerar, a partir de esa misma cita, la redefinición del mismo en la década siguiente. 
Sin dudas, a pesar de que la obra de Roberto Arlt ha sido asiduamente visitada por la crítica especializada, al menos desde la revalorización que hicieron los jóvenes de Contorno por los comienzos de los ańos 6o, Laura Juárez logra instalarse de manera sumamente productiva en la discusión. Y lo hace situándose desde «una zona crítica, cultural y literaria sobre Arlt» prácticamente inexplorada, para revelar nuevas facetas que reorganizan las piezas fundamentales del estado de la cuestión. Y no sólo nos da a conocer un Arlt diferente sino que, al ubicar esta producción en su contexto de emergencia, la autora lleva a cabo también una exhaustiva reconstrucción de las polémicas, los intereses y los proyectos estéticos e ideológicos más relevantes del campo literario y cultural de esos ańos «decisivos», como señala en la introducción, «para la consolidación de las letras argentinas» (I9).

Desde este enfoque, Juárez analiza los diversos modos de representación adoptados por Arlt en sus cuentos, crónicas, obras de teatro y ensayos — lo que llama las «distintas zonas textuales y formas escriturarias» (I5) - para mostrar que en esta literatura se resignifica (volviendo al epígrafe) la idea acerca de la imposibilidad de "trabajar una novela» (I3) como las de Flaubert, inscripta en el prólogo a Los lanzallamas. Pues ahora Arlt ya no postergará su preocupación por el estilo. En esa dirección, ensayará una escritura que se acerca — sin asimilarlos completamente, sino más bien efectuando singulares inflexiones propias- a los modelos literarios más prestigiosos y consagrados, como el modernismo o el imaginario decadente; o a aquellos otros, como el policial y el fantástico, que Jorge Luis Borges, Adolfo Bioy Casares y Silvina Ocampo comienzan a promover por esos años. Pero, además, en correlación con este viraje en sus modalidades de escritura, se esboza una figura de autor alejada de la del «torturado», «incomprendido» $\mathrm{y}$ «mal escritor» que signó su literatura de la década del 20. De ese escritor «desafiante, agónico y rupturista» de las «Aguafuertes porteñas» o de su ciclo novelístico, nos encontramos aquí con un Arlt que despliega en sus textos un saber literario y retórico de modelos consagrados por la tradición estética, que revela, en última instancia, una fuerte preocupación por la búsqueda de legitimación y jerarquización de su literatura en el campo cultural y literario. En otras palabras, se vislumbra en su literatura de los 30 una voluntad de ser reconocido por su «habilidad estilística», intentando invalidar así las acusaciones de «mal escritor» que frecuentemente se le hicieron en los ańos previos.

En cada uno de los capítulos del libro, Laura Juárez se hace cargo del estudio de esas «zonas textuales» de la producción arltiana de los años 30 a partir de un minucioso y sutil análisis tanto de los textos como de los diálogos y las discusiones que esta producción mantiene con otros actores o espacios claves del campo literario y cultural, sin olvidar sus vínculos con la coyuntura social y política de esos años. Así, para explicitar la singular inscripción de su obra en ese campo, la autora reconstruye el itinerario intelectual de Arlt en un recorrido que la lleva a considerar desde «El teatro del Pueblo» de Barletta hasta Sur, pasando por una variada cantidad de espacios intelectuales divergentes y hasta antagónicos; o desde la polémica iniciada por Ortega y Gasset sobre la novela hasta la revalorización 
borgeana del género policial y el fantástico. Y, de esta manera, Roberto Arlt en los años 30 arroja luz sobre novedosas facetas de Arlt, entre ellas: la de un cronista viajero fascinado ante los paisajes y las culturas exóticas; la de un dramaturgo que se muestra más preocupado por "sacudir al espectador" que por perseguir una finalidad pedagógica; la de un narrador cuyas ficciones pretenden acentuar la construcción de la trama, en detrimento de la centralidad que las subjetividades exacerbadas cobraban en sus novelas anteriores; o la de un ensayista que interviene en la polémica sobre la novela privilegiando "la acción" por sobre la introspección de la novela psicológica y realista. Podría decirse, en fin, que a partir de este "otro Arlt" que Laura Juárez revela en su libro, se abre el juego a nuevas lecturas de la obra del autor renovando los ejes y las perspectivas para su abordaje. 